\title{
ANÁLISE DE RISCO E CLASSIFICAÇÃO DE FORNECEDORES EM UMA CADEIA DE SUPRIMENTOS
}

\author{
Miguel Afonso Sellitto1 \\ Bruna Omizzolo Lazzarotto2 \\ Alexsander Longhi3 \\ Miriam Borchardt4 \\ Giancarlo Medeiros Pereira5
}

\begin{abstract}
Resumo: O objetivo deste artigo foi descrever o processo de avaliação de risco e classificação de fornecedores da cadeia de suprimentos de uma empresa montadora de equipamentos mecânicos. O método de pesquisa foi a modelagem qualitativa. O processo de avaliação dos fornecedores é baseado em julgamento de especialistas da empresa focal e considera quatro construtos: impacto do fornecedor nos resultados da cadeia; complexidade na gestáo do fornecedor; dependências entre fornecedor e empresa; e saúde financeira do fornecedor. Com os quatro construtos foram construídas três matrizes: impacto x complexidade; impacto x dependência; e impacto x saúde financeira. Para exemplificar o método, seis fornecedores foram avaliados. Quatro dos seis fornecedores foram diagnosticados como em situação de risco e açôes de correção foram sugeridas pela empresa. Em um deles, a situação evoluiu favoravelmente em todos os aspectos. Em dois, houve alguma evoluçáo, mas ainda insuficiente. E em um fornecedor, não houve resultado positivo e o mesmo foi excluído da cadeia.
\end{abstract}

Palavras-chave: avaliação de fornecedores, avaliação de risco, gestão de fornecedores.

Abstract: The purpose of this article was to describe the process of risk assessment and classification of suppliers in the supply chain of a company of mechanical equipment. The research method was the qualitative modeling. The process of assessment of suppliers is based on expert judgment and considers four constructs: impact of the supplier on the results of the chain; complexity in the management of the supplier; dependencies between supplier and company; and financial health of the supplier. With the constructs, three matrices were built: impact $\mathrm{x}$ complexity; impact $\mathrm{x}$ dependence; and impact $\mathrm{x}$ financial health. To illustrate the method, six suppliers were evaluated. Four out of the six were diagnosed as at risk and remediation actions have been suggested by the company. In one of them, the situation has evolved favorably in all aspects. In two, there was some progress, but still insufficient. In the last one, there was no positive result and the supplier was excluded from the chain.

Key words: supplier assessment, risk assessment, supplier management.

\footnotetext{
1 Universidade do Vale do Rio dos Sinos - UNISINOS (sellitto@unisinos.br)

2 Universidade do Vale do Rio dos Sinos - UNISINOS (brunalazzarotto@unisinos.br)

3 Universidade do Vale do Rio dos Sinos - UNISINOS (alex.longhi@ibest.com.br)

4 Universidade do Vale do Rio dos Sinos - UNISINOS (miriamb@unisinos.br)

5 Universidade do Vale do Rio dos Sinos - UNISINOS (gian@unisinos.br)
} 


\section{INTRODUÇÃO}

Desde o seu surgimento como objeto de estudos acadêmicos, nos anos 1980, cadeias de suprimentos (Supply Chain-SC) e suas técnicas de gestão (Supply Chain Management - SCM) tornaram--se importante fator de competitividade empresarial (Chow et al., 2008). Em cenários de intensa competiçáo globalizada, produtos com ciclo de vida cada vez menores e expectativa crescente por qualidade a preços acessíveis, a formação da SC e a consequente formalização da SCM tornaram-se fonte de competitividade para empresas e indústrias (Souza et al., 2012).

Em uma das primeiras definiçóes encontradas na literatura, a SC foi caracterizada como uma rede conectando diversas entidades, desde o fornecedor de matérias-primas até o cliente final, englobando operaçôes de manufatura e de serviços, e gerenciando o fluxo de materiais, informaçóes e pagamentos de modo a atender os requisitos de negócios dos clientes (Stevens, 1989). A SCM pode ser definida como a integraçáo dos principais processos de gerenciamento dos fluxos de materiais, informaçóes e financeiros entre as empresas que participam do processo de atendimento a clientes e consumidores finais (Pedroso, 2002). Na SCM, estratégias de operaçáo com foco exclusivo em provedores de serviços de logística, fornecedores, operaçóes e atendimento a consumidores foram substituídas por alianças estratégicas e relaçôes cooperativas de longo termo, nas quais fornecedores e consumidores são parceiros e não oponentes da empresa focal, ou seja, aquela que tem primazia na elaboração da estratégia (Tan et al., 1998; Lambert, 2008; Lambert e Cooper, 2000).

Na SCM, empresas focais integram-se estrategicamente com fornecedores e clientes, estabelecendo laços de confiança e açóes de cooperação e parceria (Humphreys et al., 2001). Embora cada empresa da cadeia tenha seus objetivos individuais, o objetivo da cadeia como um todo, cumulativamente, é agregar valor ao produto ou serviço que será entregue ao cliente final (Pires, 2004). É objetivo da SCM promover a sinergia entre as partes, a fim de atender o cliente final pela otimização dos processos de negócio, reduzindo custos, níveis de estoque, melhorando a qualidade e criando vantagem competitiva e valor para toda a cadeia (Alves Filho et al., 2004).

Um problema recorrente em SCM é como responder a variaçôes de demanda e lidar com situaçôes de risco, principalmente quando ocorre a entrada de mais parceiros e o consequente aumento de complexidade na cadeia (Vilko e Hallikas, 2012). Atualmente, devido ao aumento das distâncias e à rapidez das entregas, as cadeias ficaram mais suscetíveis a rupturas, crescendo de importância a gestáo do risco (Tang e Musa, 2011). Um desafio em SCM é o desenvolvimento de modelos de apoio à análise de risco e critérios de avaliação que identifiquem ambientes instáveis e previnam rupturas de suprimento e, por consequência, o desabastecimento da manufatura. Modelos de avaliação de risco e de desempenho de fornecedores são lacunas de conhecimento que podem e devem ser exploradas por futuras pesquisas (Sellitto et al., 2011).

A questáo de pesquisa deste artigo foi: como avaliar riscos e minimizar a possibilidade de haver ruptura na cadeia de suprimentos de uma empresa industrial? O objetivo principal deste artigo é descrever o processo de avaliaçáo de risco e classificação de fornecedores da cadeia de suprimentos de uma empresa montadora de equipamentos mecânicos. $\mathrm{O}$ processo de avaliação é baseado em quatro aspectos de fornecedores que sáo julgados por especialistas da empresa: impacto do fornecedor nos resultados da cadeia; complexidade na gestáo do fornecedor; dependências mútuas entre fornecedor e empresa; e saúde financeira do fornecedor. O método de pesquisa foi a modelagem qualitativa do objeto de estudo. Os objetivos secundários foram: descrever o modelo que a empresa usa; e relatar a aplicação do modelo em seis fornecedores.

O restante do artigo está organizado em: revisão; pesquisa; discussão dos resultados; e conclusóes. Parte da pesquisa foi financiada pelo CNPq.

\section{CLASSES DE FORNECIMENTOS E GESTÁO DE RISCO EM SC}

Até meados da década de 1970, a relação entre as empresas montadoras ou fabricantes de bens industriais e seus fornecedores era vista como um processo menos relevante dentro da estratégia de produçáo. Por exemplo, compartilhar tecnologia e habilidades específicas com clientes e fornecedores era considerada estratégia de risco, sendo dada pouca ênfase à cooperação e às parcerias (Ellran e Carr, 1994). A partir dos anos 1980, com a disseminação de estratégias de produção baseadas na lógica just-in-time, observaram-se benefícios e vantagens de competição originadas de relaçóes cooperativas com fornecedores. Tais relaçóes incluíram compartilhamento de informações e habilidades e permitiram simultaneamente redução nos níveis de estoque e aumento nos níveis de serviço a clientes. Em sín- 
tese, houve aumento na capacidade de competição baseada em custos e em prestação de serviço de empresas que operavam em uma lógica de cooperação coordenada em suas SC (Pires, 1998; Scavarda e Hamacher, 2001).

Também foram observadas redução nos tempos para o desenvolvimento de novos produtos e nos tempos até a entrega de produtos finais (Fu e Piplani, 2004). Por outro lado, aumentou a complexidade da cadeia como um todo, aumentando as chances de ruptura nas linhas de abastecimento, o que aumentou a importância de se gerenciar o risco na cadeia (Sodhi et al., 2012).

Uma SC pode ser definida como uma rede de entidades de negócios autônomos ou semiautônomos, responsáveis pelas atividades de compras, fornecimentos, produção e distribuição associadas com uma ou mais famílias de produtos (Swaminathan et al., 1996). Uma SC é uma rede de empresas que compram matérias-primas, transformam-nas em produtos intermediários e depois em produtos finais, que serão distribuídos para venda e consumo. Algumas vezes, a SC inclui a prestação de serviços associados ao produto (Lee e Billington, 1995). A SCM é o processo integrado segundo o qual as empresas da SC operam em conjunto para obter suas matérias-primas, transformá-las em produtos e distribuí-los para venda (Beamon, 1998). Mais recentemente, o retorno de materiais pós-venda e pós-consumo foi acrescido à SCM. Passou a ser responsabilidade da SCM a busca e a reintegração de bens ou resíduos retornáveis a outros processos produtivos ou ao menos sua correta destinação ambiental (Sellitto et al., sd).

$\mathrm{Na}$ perspectiva de cadeia, uma empresa não pode mais ser vista isoladamente, mas sim como parte de uma rede de colaboração e cooperação estratégica na qual as relaçóes entre as empresas devem ser gerenciadas segundo objetivos de competição (Cheung e Rowlinson, 2011). Em síntese, a competição não ocorre mais entre empresas isoladas, mas entre cadeias de empresas (Pires, 2004).

Uma SC engloba todos os estágios (clientes, varejistas, distribuidores, fabricantes e fornecedores) envolvidos no atendimento de um pedido de cliente (Chopra e Meindl, 2003). Para Lumus et al. (1998), a SC é como uma rede de entidades pelas quais perpassam os fluxos de materiais, informaçóes e pagamentos. Cabe à SCM o controle e a coordenação destes fluxos, segundo requisitos de negócios estabelecidos pelos parceiros e principalmente pelos clientes. Neste contexto, pode haver incerteza sobre a estratégia de cadeia e como relacionar esta estratégia comum com as estratégias individuais dos membros. É necessária gestão do risco que surge para lidar com incertezas e potenciais perdas acarretadas por eventuais rupturas na cadeia. Conforme Zsidisin et al. (2004), a avaliação dos riscos organizacionais exige identificar possíveis perdas, sua extensão dentro da cadeia, a probabilidade de ocorrência e da severidade de suas consequências e a avaliaçáo global da complexidade das operaçóes envolvidas (Giannakis e Louis, 2011). A gestáo do risco e do relacionamento com o fornecedor é importante, haja vista que, em algumas SC, os fornecimentos podem chegar a $90 \%$ dos gastos totais da empresa focal (Green et al., 1996). Tais avaliações são atividades fundamentais em gestão de suprimentos (Moon e Tikoo, 2002).

Alguns fatores devem ser considerados na avaliação de risco (Zsidisin et al., 2004): (i) riscos econômicos, que incluem flutuaçôes de taxas de câmbio, impostos, juros, falências de clientes e fornecedores; (ii) riscos políticos, que incluem disputas comerciais entre países, embargos econômicos, ou conflitos armados; (iii) riscos geográficos ou naturais, que incluem desastres naturais em consequência de fatores climáticos; e (iv) riscos de planejamento, que incluem erros de projeto e de processo e problemas de desabastecimento ou ruptura na cadeia. Hahn e Kuhn (2012) associam o risco à criação de valor na cadeia, minimizando riscos naquelas atividades com mais capacidade de geração de valor do ponto de vista dos investidores.

Uma abordagem usada na literatura para gestáo de riscos em cadeias de suprimentos é a classificação dos fornecimentos (e eventualmente dos fornecedores) segundo critérios que possam ser avaliados por decisores ou por especialistas.

Uma classificação preliminar que pode ser útil no processo de avaliação é a curva $A B C$. $A$ curva $A B C$ classifica itens e fornecedores conforme sua importância relativa, dada pelo percentual do item em relação ao custo total das aquisiçôes. Gonçalves (2007) define: (i) classe A são itens mais importantes que devem ter uma estratégia especial de gestão; (ii) classe B são itens em situação intermediária; e (iii) classe $\mathrm{C}$ são itens menos importantes que justificam uma estratégia comum simplificada. Brown (1967) observa que, dados os percentuais gastos com os fornecedores, pode ser usado um modelo lognormal para definir de modo analítico a curva $\mathrm{ABC}$ e os limites entre as classes. Uma variante é a análise XYZ, que considera risco ao invés de custo (Klippel et al., 2007). Outra variante considera a variabilida- 
de na evolução temporal da demanda dos itens, ao invés de custo ou risco (Beck et al., 2009).

A Figura 1 apresenta um modelo típico de curva $A B C$ para as compras de uma manufatura. $\mathrm{Na}$ figura, cerca de $10 \%$ do itens respondem por cerca de $70 \%$ do volume de dispêndios com compras (Rosa et al., 2006).

Figura 1: Curva $A B C$

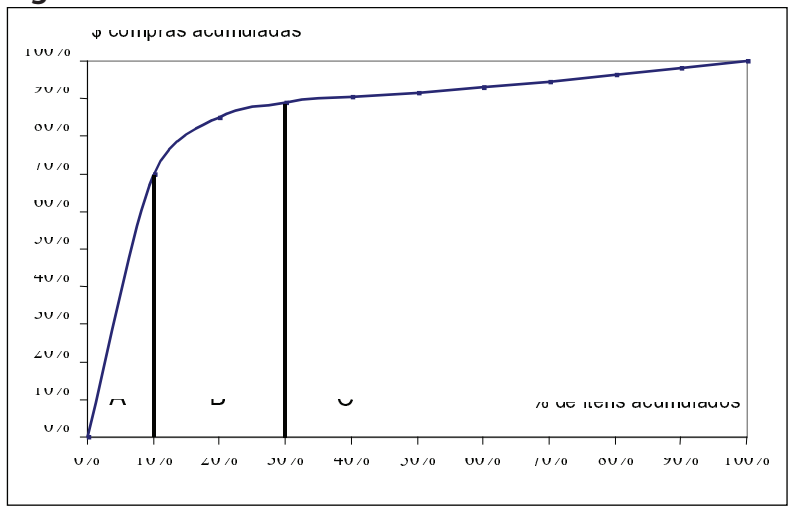

Outro tipo de instrumento de classificaçáo de fornecedores são as matrizes bidimensionais.

Dornier et al. (2000) apresentam a matriz de importância estratégica e criticidade (IEC), que relaciona o valor estratégico do componente e a sua criticidade, ou seja, o seu risco de desabastecimento. $\mathrm{O}$ valor estratégico do componente inclui a complexidade tecnológica, o impacto nos resultados, a propriedade ou náo da tecnologia empregada e a escassez de alternativas, entre outros. A criticidade inclui o valor percentual do item em relação ao conjunto de compras e o grau de dependência do produto final em relação ao componente. Altas importância e criticidade implicam que a empresa deva ter domínio e se possível exclusividade ou até mesmo a propriedade física e intelectual do item. Alta importância e baixa criticidade implicam a possibilidade de inovação: se a mesma der errado, não é crítica, mas se der certo, há salto significativo de desempenho. Baixa importância e alta criticidade implicam contratos de longo prazo e cláusulas de garantia de fornecimento para prevenir a falta, pois os efeitos do desabastecimento são severos. Finalmente, baixas importância e criticidade implicam política de livre-mercado, o que significa busca permanente pelo menor preço e por outras facilidades inerentes ao processo de negociação (Dornier et al., 2000).

Outro tipo de matriz surge em Klippel et al. (2007). Os autores relacionaram influência no resultado que um fornecimento acarreta com o risco de desabastecimento. A influência é avaliada ava- liando-se o impacto que o item causa no resultado das principais dimensóes estratégicas da manufatura (custo, qualidade, flexibilidade, entrega, etc.). O risco de desabastecimento é avaliado considerando-se o poder de barganha dos fornecedores, a facilidade de eventual substituição de fornecedor, a rivalidade no fornecimento, e eventuais barreiras de entrada a fornecedores alternativos. Altas influência e risco definem os materiais estratégicos, ou seja, aquele sobre os quais se deve ter domínio ou ao menos planos de contingência negociados e definidos entre as partes. Alta influência e baixo risco definem os materiais de competição, que auxiliam a empresa focal na busca da competitividade da cadeia. Baixa influência e alto risco definem os itens de risco, que não podem faltar, sob pena de severas perdas. Por fim, baixas influência e risco definem os itens de livre-mercado, com os quais se deve buscar redução de custo e outras vantagens de competição pela permanente negociação com o mercado e com fornecedores alternativos (Klippel et al., 2007).

Por fim, uma terceira forma surge em Pires (2004), que cita Handfield et al. (2000): oportunidade combinada com risco contra volume de compras. As classes são: (i) altas oportunidade e risco e baixo volume: itens monopolizados ou críticos; (ii) altas oportunidade e risco e alto volume: itens estratégicos; (iii) baixas oportunidade e risco e baixo volume: itens náo-críticos; e (iv) baixas oportunidade e risco e alto volume: itens padronizados e substituíveis.

\section{A PESQUISA}

O método de pesquisa foi a modelagem qualitativa. Segundo Roesch (1999), a pesquisa qualitativa deve ser utilizada em uma fase exploratória, onde se busca obter mais informaçóes sobre um objeto. Para estudos mais aprofundados sobre o objeto da pesquisa qualitativa, Yin (2001) aponta o estudo de caso em profundidade como método de pesquisa.

Foi modelada a avaliaçáo feita pela empresa focal de uma SC fabricante e montadora de equipamentos mecânicos localizada na regiáo sul do Brasil. A empresa focal (montadora) recebe componentes e subsistemas de fornecedores e monta o produto final. A cadeia tem cerca de 300 fornecedores, sendo que $35 \%$ são de fora do país.

Em meados de 2008, a cadeia enfrentou grave desabastecimento do componente $\mathrm{XX}$, simples e de baixo custo, mas que impedia a montagem final e a entrega dos equipamentos. O desabasteci- 
mento ocorreu em função de problemas financeiros do fornecedor que, ao final de seis meses, encerrou atividades. XX era fornecido por fornecedor local que apresentava bom escore nas avaliaçóes anuais de fornecedores. Não havia fornecedor substituto já desenvolvido, justamente pelo bom escore de desempenho que o fornecedor ostentava até então.

O método de avaliação anterior considerava apenas quatro elementos ligados à estratégia de produçáo da empresa: qualidade, custo, entrega e relacionamento. Era obtido um escore médio destes elementos, que era então relacionado ao risco de desabastecimento. Caso tanto o risco como o impacto fossem altos, a empresa tomava açóes corretivas. Problemas de saúde financeira e de excessiva dependência entre as partes não eram detectados pelo sistema de avaliação. A avaliação era aplicada exclusivamente aos fornecedores classe A da curva ABC da empresa. Quando o fornecedor apresentava escore abaixo do desejado, era acionado. Caso a situação não fosse alterada, o mesmo era descontinuado.

Quando ocorreu o desabastecimento, a SCM foi questionada quanto à validade da avaliaçáo e como essa poderia ser melhorada para prever situaçôes críticas e de risco envolvendo fornecedores. Com base nesse questionamento, a SCM concluiu que o método avaliava só o aspecto técnico e produtivo do fornecedor, desconsiderando por exemplo a sua imagem perante o mercado, o que pode afetar seu crédito; a complexidade de seu gerenciamento, o que envolve grau de exclusividade no uso de insumos; o grau de diferenciaçáo da empresa e da indústria, o que pode envolver previsões imprecisas; mercado errático e poder de barganha; ameaças e oportunidades, entre outros, além da situação financeira da empresa. A partir dessa constatação, foi desenvolvido um método considerando mais aspectos que pudessem afetar e colocar em risco o abastecimento da cadeia.

\subsection{MÉTODO DE CLASSIFICAÇÃO DE FORNECEDORES}

O novo método passou a analisar semestralmente cerca de 60 fornecedores classe A da empresa focal. Estes totalizam cerca de $90 \%$ dos gastos com compras da empresa. Da análise resultam projetos de melhoria conduzidos pela empresa focal. A cada reunião de análise, a nova situação de cada fornecedor é analisada para verificar a efetividade das açôes de melhorias.

O novo método passou a considerar os seguintes elementos para a avaliação: (i) complexidade no gerenciamento (o que indica o maior ou menor risco de desabastecimento); (ii) impacto que o fornecedor causa no resultado da empresa; (iii) relaçóes de dependência entre comprador e fornecedor e vice-versa; e (iv) saúde financeira do fornecedor. Três análises cruzadas são feitas para avaliar os fornecedores: (i) complexidade no gerenciamento $\mathrm{x}$ impacto no resultado (Matriz de Posicionamento Estratégico de Fornecedores - MPEF); (ii) dependência $\mathrm{x}$ impacto no resultado (Matriz de Dependência do Fornecedor - MDF); e (iii) saúde financeira $\mathrm{x}$ impacto no resultado (Supplier On The Spot - SOTS).

Para avaliar os indicadores, a SCM construiu uma base teórica que incluiu a análise das forças de competição na indústria (poder de barganha; rivalidade na indústria; substituição do fornecedor; e barreiras para entrada de concorrentes), citadas por Porter (1998), e as dimensôes tipicamente consideradas em estratégia de produção aplicada à manufatura: (i) custo do fornecimento; (ii) qualidade de conformação a especificaçóes do fornecimento; (iii) responsividade temporal, avaliada como capacidade de entregar os itens no prazo e capacidade de responder de forma ágil a alteraçôes; e (iv) tecnologia, que avalia o nível tecnológico do fornecedor e sua capacidade de responder às demandas, citadas por Slack (2002).

Para a avaliação, são empregados indicadores categóricos, distribuídos entre: complexidade, impacto e dependência. Para cada indicador, o grupo de especialistas atribui um escore que varia entre 0 (pouco influente) e 5 (muito influente). São produzidos escores individuais para os conceitos, obtidos pela média das respostas aos indicadores. O escore do construto é a média dos escores dos conceitos.

Eventualmente, para casos em que os indicadores tenham impactos diferentes no construtos, métodos de distribuição de importância relativa, tais como os métodos multicriteriais de apoio à decisão, podem ser usados (Sellitto, 2005).

Para avaliar a saúde financeira de fornecedores, é usada uma escala construída pela SERASA, variando de 1 a 22 ( 1 = saúde plena; 22 = empresa falimentar). A saúde financeira aproveita a escala de 0 a 22 da SERASA. A estrutura de avaliação é mostrada no Quadro 1. 


\begin{tabular}{|c|c|}
\hline CONSTRUTO & $\begin{array}{c}\text { INDICADOR } \\
(0=\text { POUCO INFLUENTE, ,.., } 5=\text { MUITO INFLUENTE) }\end{array}$ \\
\hline \multirow{6}{*}{ Complexidade na gestão } & Grau de exclusividade do insumo do item \\
\hline & Grau de diferenciação do item na empresa fornecedora \\
\hline & Grau de diferenciação do fornecedor na indústria \\
\hline & Existência ou facilidade para substituiç̧ão do item \\
\hline & Grau de diferenciação do produto que usa o item \\
\hline & Nível de excelência individual exigida do fornecedor \\
\hline \multirow{9}{*}{ Impacto nos resultados } & Importância do item para o produto do comprador \\
\hline & Curva de experiência do fornecedor \\
\hline & Custo de mudança do fornecedor \\
\hline & Custo do fornecimento em relação aos concorrentes \\
\hline & Economia de escala na compra do item \\
\hline & Necessidade de capital para a compra do item \\
\hline & Possibilidade de integração do item na indústria \\
\hline & Existência de materiais substitutos para o caso de atraso \\
\hline & Tipo de risco se o fornecedor atrasar \\
\hline \multirow{10}{*}{ Dependência } & Nível de importância do comprador para o fornecedor \\
\hline & Nível de importância do fornecedor para o comprador \\
\hline & Grau de concentração e tamanho dos fornecedores \\
\hline & Existência de materiais que possam substituir o item \\
\hline & Equilíbrio na indústria e entre concorrentes \\
\hline & Acesso às fontes de matéria-prima \\
\hline & Acesso aos canais de distribuição \\
\hline & Políticas governamentais \\
\hline & Mercado potencial para o item \\
\hline & Dificuldade para mudar de fornecedor \\
\hline
\end{tabular}

A primeira análise cruzada relaciona complexidade no gerenciamento com impacto no resultado, formando a Matriz de Posicionamento Estratégico de Fornecedores (MPEF). Segundo o quadrante em que o fornecedor se encontra, quatro situaçôes são possíveis: (i) alta complexidade e alto impacto (fornecedores estratégicos, que exigem uma abordagem especial); (ii) alta complexidade e baixo impacto (fornecedores de risco, com potencial de risco); (iii) baixa complexidade e alto impacto (fornecedores competitivos, que ajudam na competição); e (iv) baixa complexidade e baixo impacto (livre mercado).

O Quadro 2 sintetiza as situações abordadas pela matriz.

Quadro 2: Análise estratégica para a relação entre complexidade e impacto nos resultados

\begin{tabular}{|c|c|c|c|c|}
\hline COMPLEXIDADE & IMPACTO & AMBIENTE DE NEGÓCIOS & ANÁLISE ESTRATÉGICA & ALTERNATIVAS \\
\hline Alta & Alto & Q1 - Fornecedores estratégicos & $\begin{array}{l}\text { Situação problemática: restrições legais, } \\
\text { monopólios, especificaçõos técnicas críticas, } \\
\text { grandes volumes. }\end{array}$ & $\begin{array}{l}\text { Parcerias de longo prazo e garantias contratuais de } \\
\text { fornecimento para reduzir risco. }\end{array}$ \\
\hline Alta & Baixo & Q2 - Fornecedores de risco & $\begin{array}{l}\text { Situação potencialmente perigosa: poucos } \\
\text { concorrentes, pequenos volumes, prazos longos } \\
\text { e incertos. }\end{array}$ & $\begin{array}{l}\text { Desenvolver alternativas e formar estoque para } \\
\text { reduzir risco. }\end{array}$ \\
\hline Baixa & Alto & Q3 - Fornecedores competitivos & $\begin{array}{l}\text { Situação equilibrada: muitos concorrentes, grandes } \\
\text { volumes, prazos longos. }\end{array}$ & Dividir volume e risco entre vários fornecedores. \\
\hline Baixa & Baixo & Q4 - Fornecedores de mercado & $\begin{array}{l}\text { Situação segura: muitos concorrentes, pequenos } \\
\text { volumes, opções imediatas. }\end{array}$ & $\begin{array}{l}\text { Livre concorrência e concentração de compras para } \\
\text { baixar preço. }\end{array}$ \\
\hline
\end{tabular}

A segunda análise cruzada relaciona impacto no resultado com dependência, formando a Matriz de Dependência do Fornecedor - MDF. Segundo o quadrante em que o fornecedor se encontra, quatro situaçôes são possíveis: (i) alta dependência e alto impacto (fornecedores com interdependência elevada); (ii) alta dependência e baixo impacto (fornecedores dependentes e seguros); (iii) baixa dependência e alto impacto (fornecedores de risco); e (iv) baixa dependência e baixo impacto (livre mercado). 
O Quadro 3 sintetiza as situaçôes abordadas pela matriz.

Quadro 3 : Análise estratégica para a relação entre impacto nos resultados e dependência

\begin{tabular}{|c|c|c|c|c|}
\hline DEPENDÊNCIA & IMPACTO & AMBIENTE DE NEGÓCIOS & ANÁLISE ESTRATÉGICA & ALTERNATIVAS \\
\hline Alta & Alto & $\begin{array}{l}\text { Q1 - Fornecedores } \\
\text { interdependentes }\end{array}$ & $\begin{array}{l}\text { Situação potencialmente perigosa: poucos } \\
\text { concorrentes, grandes volumes, tecnologia avançada. }\end{array}$ & $\begin{array}{l}\text { Parcerias de longo prazo e garantias contratuais } \\
\text { de fornecimento para reduzir risco. }\end{array}$ \\
\hline Alta & Baixo & Q2 - Fornecedores dependentes & $\begin{array}{l}\text { Situação segura: pequenos fornecedores com grandes } \\
\text { volumes }\end{array}$ & $\begin{array}{l}\text { Monitorar a situação e desenvolver alternativas } \\
\text { eventuais para reduzir volumes. }\end{array}$ \\
\hline Baixa & Alto & Q3 - Fornecedores de risco & $\begin{array}{l}\text { Situação de risco: poucos concorrentes, pequenos } \\
\text { volumes, especificações rigorosas, tecnologia. }\end{array}$ & $\begin{array}{l}\text { Desenvolver alternativas para simplificar produto } \\
\text { e reduzir riscos. }\end{array}$ \\
\hline Baixa & Baixo & Q4 - Fornecedores de mercado & $\begin{array}{l}\text { Situação equilibrada: muitos concorrentes, pequenos } \\
\text { volumes, opções imediatas. }\end{array}$ & $\begin{array}{l}\text { Livre concorrência e concentração de compras } \\
\text { para baixar preço. }\end{array}$ \\
\hline
\end{tabular}

A terceira análise cruzada relaciona criticidade com saúde financeira, formando a Matriz Supplier On The Spot - SOTS. Segundo o quadrante em que o fornecedor se encontra, quatro situações são possíveis: (i) alta saúde financeira e alto impacto (fornecedores críticos); (ii) alta saúde financeira e baixo impacto (fornecedores seguros); (iii) baixa saúde financeira e alto impacto (fornecedores de risco); e (iv) baixa saúde financeira e baixo impacto (fornecedores problemáticos).

O Quadro 4 sintetiza as situaçóes abordadas pela matriz.

Quadro 4 : Análise estratégica para a relação entre criticidade e saúde financeira

\begin{tabular}{|c|c|c|c|c|}
\hline $\begin{array}{c}\text { SAÚDE } \\
\text { FINANCEIRA }\end{array}$ & IMPACTO & AMBIENTE DE NEGÓCIOS & ANÁLISE ESTRATÉGICA & ALTERNATIVAS \\
\hline Alta & Alto & Q1 - Fornecedores críticos & $\begin{array}{l}\text { Situação equilibrada: poucos concorrentes, grandes } \\
\text { volumes, prazos longos e incertos. }\end{array}$ & $\begin{array}{l}\text { Desenvolver alternativas eventuais para reduzir } \\
\text { riscos. }\end{array}$ \\
\hline Alta & Baixo & Q2 - Fornecedores seguros & $\begin{array}{l}\text { Situação segura: pequenos volumes, opções imediatas } \\
\text { e de mercado, boa gestão. }\end{array}$ & Monitorar eventualmente a evolução. \\
\hline Baixa & Alto & Q3 - Fornecedores de risco & $\begin{array}{l}\text { Situação de risco: poucos concorrentes, pequenos } \\
\text { volumes, baixa rentabilidade, problemas de gestão. }\end{array}$ & $\begin{array}{l}\text { Monitoração contínua e desenvolver alternativas } \\
\text { imediatas para reduzir risco. }\end{array}$ \\
\hline Baixa & Baixo & Q4 - Fornecedores problemáticos & $\begin{array}{l}\text { Situação potencialmente perigosa: Pequenos } \\
\text { volumes, opções imediatas e de mercado, má gestão. }\end{array}$ & apoiar o fornecedor mas desenvolver alternativas. \\
\hline
\end{tabular}

A avaliação pelo método é conduzida por um comitê de especialistas e ocorre a cada seis meses. Após a construção, as matrizes são levadas a um comitê estratégico de especialistas formado pela alta direção da empresa, que avalia os resultados e as recomendaçóes do comitê e determina açóes de correção. Espera-se que os resultados das açóes sejam observados na próxima rodada de avaliação, em seis meses. A evoluçáo dos resultados ao longo do tempo e a própria eficiência do método também é examinada pelo comitê estratégico da empresa.

Para exemplificar a aplicação do método de avaliação para a gestão de risco, analisar alguns resultados e o tipo de contribuição esperada, selecionaram-se seis fornecedores e fornecimentos e estudaram-se seus resultados.

\subsection{CASO DE APLICAÇÃO: SEIS FORNECEDORES AVALIADOS}

Selecionaram-se seis fornecimentos que foram avaliados. Procurou-se escolher fornecimentos ligados a fornecedores com características empresariais e com posiçôes na curva $A B C$ distintas para verificar a resposta do método em diferentes cenários. O Quadro 5 traz as características das empresas que foram consideradas para os exemplos de avaliaçáo.

Quadro 5 : Características dos fornecedores pesquisados

\begin{tabular}{|c|c|c|}
\hline FORNECIMENTO & CARACTERÍSTICAS DO FORNECEDOR ATUAL & $\%$ NA CURVA ABC \\
\hline A & Empresa de pequeno porte familiar, que fornece componente metálicos para as produtos comerciais. & $0,97 \%$ \\
\hline B & Empresa de médio porte, que fornece chapas metálicos para toda linha de produto & $4,47 \%$ \\
\hline C & Empresa de médio porte, que fornece componentes plásticos para a linha residencial & $1,11 \%$ \\
\hline D & Empresa de médio porte, que fornece componentes plásticos para a linha residencial & $2,88 \%$ \\
\hline E & Empresa multinacional que fornece um dos produtos mais críticos do produto final & $11,28 \%$ \\
\hline $\mathrm{F}$ & Empresa de médio porte, que fornece componentes plásticos para a linha residencial & $0,025 \%$ \\
\hline
\end{tabular}


A Figura 2 apresenta de forma gráfica a avaliação [complexidade $\mathrm{x}$ impacto nos resultados] feita para os seis fornecedores. Na matriz MPEF formada, quatro fornecimentos ou fornecedores $(A, D$, E e F) ocupam posiçóes no quadrante de alta complexidade e alto impacto, representando algum tipo de risco que deverá ser gerenciado. Dois ocupam respectivamente os quadrantes de alta complexidade e baixo impacto e de baixa complexidade e baixo impacto.

Figura 2 : Matriz MPEF para os seis casos

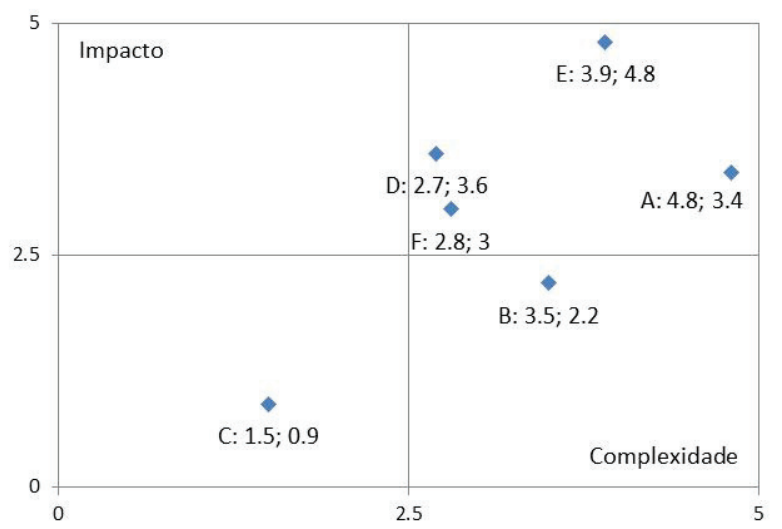

A Figura 3 apresenta de forma gráfica a avaliação [impacto nos resultados $\mathrm{x}$ dependência] feita para os seis fornecimentos. Na matriz MDF formada, quatro fornecedores (A, D, E e F) ocupam posições no quadrante de alto impacto e baixa dependência, representando algum tipo de risco que deverá ser gerenciado. Dois fornecedores (B e C) ocupam o quadrante de baixo impacto e baixa dependência.
Figura 3 : Matriz MDF para os seis casos

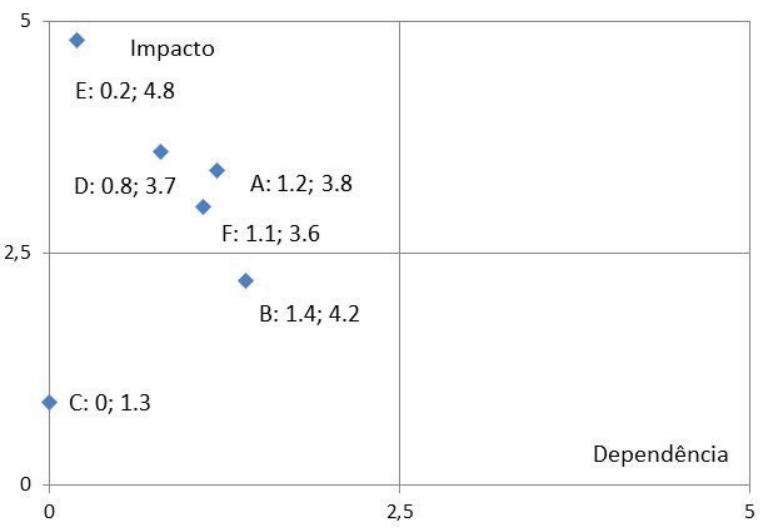

A Figura 4 apresenta de forma gráfica a avaliaçáo [impacto nos resultados x saúde financeira] feita para os seis fornecimentos. Na matriz STOS formada, apenas um fornecedor (E) ocupa posição no quadrante de baixa saúde financeira e alto impacto, representando algum tipo de risco que deverá ser gerenciado.

Figura 4 : Matriz STOS para os seis casos

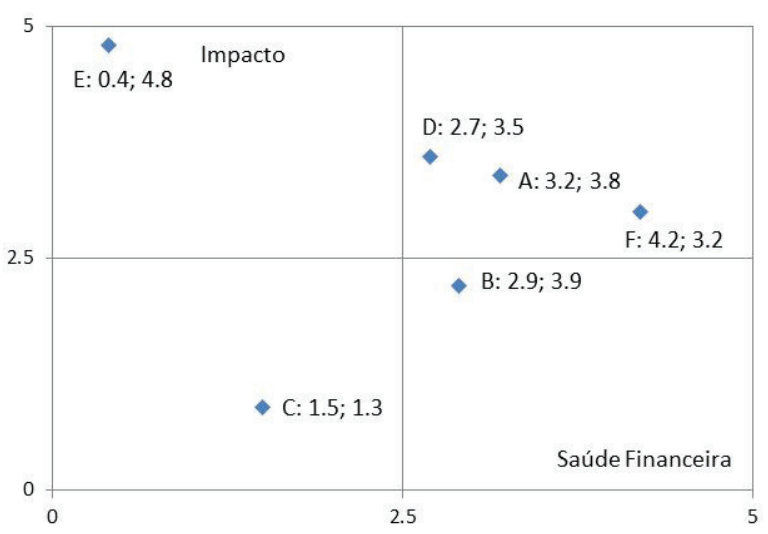

O Quadro 6 sintetiza a avaliação.

Quadro 6: Síntese da avaliação dos seis fornecedores

\begin{tabular}{|c|c|c|c|c|}
\hline FORNECIMENTO & MPEF & MDF & STOS & ANÁLISE DA SITUAÇÃO \\
\hline A & $\begin{array}{l}\text { Q1 (alta complexidade, } \\
\text { alto impacto) }\end{array}$ & $\begin{array}{l}\text { Q3 (baixa dependência, } \\
\text { alto impacto) }\end{array}$ & $\begin{array}{l}\text { Q1 (alta saúde financeira, } \\
\text { alto impacto) }\end{array}$ & $\begin{array}{l}\text { Situação de risco por complexidade na gestão e alto impacto nos } \\
\text { resultados: parcerias de longo prazo. }\end{array}$ \\
\hline B & $\begin{array}{l}\text { Q2 (alta complexidade, } \\
\text { baixo impacto) }\end{array}$ & $\begin{array}{l}\text { Q3 (baixa dependência, } \\
\text { baixo impacto) }\end{array}$ & $\begin{array}{l}\text { Q1 (alta saúde financeira, } \\
\text { baixo impacto) }\end{array}$ & $\begin{array}{l}\text { Situação potencialmente perigosa por alta complexidade: desenvolver } \\
\text { alternativas eventuais de fornecimento. }\end{array}$ \\
\hline C & $\begin{array}{l}\text { Q4 (baixa complexidade, } \\
\text { baixo impacto) }\end{array}$ & $\begin{array}{l}\text { Q4 (baixa dependência, } \\
\text { baixo impacto) }\end{array}$ & $\begin{array}{l}\text { Q4 (baixa saúde } \\
\text { financeira, baixo impacto) }\end{array}$ & $\begin{array}{l}\text { Situação potencialmente perigosa por baixa saúde financeira: apoiar o } \\
\text { fornecedor mas desenvolver alternativas. }\end{array}$ \\
\hline D & $\begin{array}{l}\text { Q1 (alta complexidade, } \\
\text { alto impacto) }\end{array}$ & $\begin{array}{l}\text { Q3 (baixa dependência, } \\
\text { alto impacto) }\end{array}$ & $\begin{array}{l}\text { Q1 (alta saúde financeira, } \\
\text { alto impacto) }\end{array}$ & $\begin{array}{l}\text { Situação de risco por baixa dependência e alto impacto nos } \\
\text { resultados: desenvolver alternativas de fornecimento. }\end{array}$ \\
\hline$E$ & $\begin{array}{l}\text { Q1 (alta complexidade, } \\
\text { alto impacto) }\end{array}$ & $\begin{array}{l}\text { Q3 (baixa dependência, } \\
\text { alto impacto) }\end{array}$ & $\begin{array}{c}\text { Q3 (baixa saúde } \\
\text { financeira, alto impacto) }\end{array}$ & $\begin{array}{l}\text { Situação de risco por baixas dependência e saúde financeira e } \\
\text { altos impacto e criticidade: apoiar o fornecedor mas desenvolver } \\
\text { alternativas de fornecimento. }\end{array}$ \\
\hline$F$ & $\begin{array}{l}\text { Q1 (alta complexidade, } \\
\text { alto impacto) }\end{array}$ & $\begin{array}{l}\text { Q3 (baixa dependência, } \\
\text { alto impacto) }\end{array}$ & $\begin{array}{l}\text { Q1 (alta saúde financeira, } \\
\text { alto impacto) }\end{array}$ & $\begin{array}{l}\text { Situação de risco por complexidade na gestão, baixa dependência e } \\
\text { alto impacto: parcerias de longo prazo e desenvolver alternativas de } \\
\text { fornecimento. }\end{array}$ \\
\hline
\end{tabular}




\subsection{Discussão e Evoluçáo dos Casos Avaliados}

Observa-se que todos os seis casos apresentam ou alguma situação de risco ou alguma situação potencialmente perigosa, ou seja, que pode evoluir e vir a tornar-se uma situação de risco.

O fornecedor A apresenta alto impacto nos resultados e sua gestão é de alta complexidade. A gestão exige estrutura administrativa específica que acarreta custos elevados. Pode eventualmente haver erros administrativos ou de planejamento que podem levar a uma desistência do fornecedor em continuar operando na cadeia. Para simplificar os procedimentos e garantir a continuidade do abastecimento, sugere-se estabelecer uma parceria de longo prazo que garanta o fornecimento, remova procedimentos onerosos e repetitivos e satisfaça o fornecedor, garantindo a continuidade da relação.

O fornecedor B depende muito pouco da empresa compradora. Sua gestão também é de alta complexidade, tem boa situação financeira e pode se desinteressar a qualquer momento de continuar operando na cadeia. Sugere-se desenvolver uma alternativa para este fornecedor para ser usada eventualmente, caso este encontre dificuldades ou demonstre desinteresse em continuar a relação.

O fornecedor $\mathrm{C}$ poderia representar uma situação segura, devido às suas baixas complexidade e impacto nos resultados. No entanto, como depende pouco da empresa e tem uma situação financeira periclitante, oferece uma situação de risco potencial. Sugere-se apoio ao fornecedor, mas já pensando em uma alternativa caso ele não reverta sua situação.

O fornecedor $\mathrm{D}$ também depende muito pouco da empresa compradora e pode desinteressar-se de continuar operando na cadeia. Sugere-se desenvolver alternativas de fornecimento e colocá-las em práticas para diminuir os volumes contratados e reduzir os riscos existentes.

No caso do fornecedor E, a empresa compradora é mais dependente dele do que ele da compradora. Adicionalmente, o fornecedor tem problemas financeiros importantes, que levaram os especialistas a considerarem-no como de risco. Caso este fornecedor não consiga arcar com seus compromissos com terceiros, pode haver ruptura no abastecimento. A situação se agrava dada a criticidade do fornecimento, ou seja, ao natural já há possibilidade de ruptura da cadeia. Como o fornecedor tem alto impacto nos resultados da cadeia, observa-se uma situação de risco que deve ser gerenciada, por exemplo, com apoio ao fornecedor, mas já pensando em uma alternativa caso ele não se mostre capaz de reverter sua situação.
No caso do fornecedor F, a situação de risco surgiu devido à complexidade na gestáo, à baixa dependência dele em relaçáo à empresa compradora e o alto impacto representado nos resultados da cadeia. Sugerem-se parcerias de longo prazo com este fornecedor para reduzir os riscos de que a complexidade de gestáo faça ele se desinteressar e também desenvolver alternativas eventuais de fornecimento, caso o fornecimento seja descontinuado.

Como ações corretivas, a empresa determinou a elaboração de planos de ação para as empresas com situações de risco (A, D, E e F). Os demais fornecedores foram apenas informados do resultado da avaliaçáo, devido à incapacidade de gerenciar todos os fornecedores, dados os recursos finitos de controle da SCM.

Com A, a empresa iniciou tratativas para o estabelecimento de contrato de colaboração de longo prazo, até cinco anos, com cláusulas favoráveis a ambas as partes. Deste modo, afastou-se o risco de a empresa desinteressar-se pela continuidade do abastecimento. Na mais recente avaliação de posicionamento estratégico, o fornecedor A passou de alta complexidade e alto impacto para alta complexidade e baixo impacto. $\mathrm{Na}$ avaliação de dependência, A passou de baixa dependência e alto impacto para baixa dependência e baixo impacto. Em saúde financeira, A passou de boa saúde e alto impacto para boa saúde e baixo impacto. Portanto, a situação do fornecedor evoluiu favoravelmente segundo a avaliação.

Para os demais casos, a decisão foi encontrar e desenvolver fornecedores alternativos que pudessem complementar ou eventualmente substituir os atuais, diminuindo a atual dependência e aumentando o poder de barganha da empresa compradora. Açóes foram adotadas e acompanhadas pelo sistema de avaliaçáo por dois anos. Houve mudanças que vêm sendo gerenciadas na situação de todos os fornecedores, menos de F, que decidiu afastar-se da cadeia. Sua continuidade demandaria o atendimento de novas exigências da SCM que não foram bem recebidas pelo fornecedor.

O fornecedor B passou de alta complexidade, baixa dependência, alta saúde financeira e alto impacto para: baixa complexidade, alta dependência, boa saúde financeira e alto impacto. Houve troca de posição, porém sem vantagem. Outra abordagem deve ser tentada.

O fornecedor $\mathrm{C}$ passou de baixa complexidade, baixa dependência, má saúde financeira e baixo impacto; para: baixa complexidade, alta dependên- 
cia, boa saúde financeira e alto impacto. Houve troca de posição, porém sem vantagem. Outra abordagem deve ser tentada.

O fornecedor $\mathrm{D}$ passou de alta complexidade, baixa dependência, boa saúde financeira e alto impacto; para: baixa complexidade, alta dependência, boa saúde financeira e baixo impacto. Houve troca de posição com vantagem. Porém uma abordagem adicional deve ser tentada, pois a dependência subiu.

O fornecedor E passou de alta complexidade, baixa dependência, má saúde financeira e alto impacto; para: baixa complexidade, alta dependência, boa saúde financeira e alto impacto. Houve troca de posição com vantagem. Porém uma abordagem adicional deve ser tentada, pois para este fornecedor a dependência da empresa compradora também subiu.

Uma modificação de posição que não era esperada foi observada. Alguns fornecedores tiveram sua situação melhorada, tanto reduzindo complexidade como impacto nos resultados, o que é desejável. Geralmente, tais observaçóes são decorrência de processos de simplificação na gestão, que resultam em redução de custos de transação e consequentes aumentos na escala de compras. No entanto, tais melhorias, ao mesmo tempo que tornam o fornecedor mais atrativo, aumentam a relação de mútua dependência, o que pode não ser desejável. Novas açóes de controle são requeridas para que se encontrem novos pontos de equilíbrio na relaçáo entre a SCM e o fornecedor.

\section{CONSIDERAÇÓES FINAIS}

O objetivo principal deste artigo foi analisar o processo de avaliaçáo de risco de fornecedores da cadeia de uma grande empresa da indústria metal-mecânica. $\mathrm{O}$ método de pesquisa foi a modelagem qualitativa. O método de avaliação foi exemplificado relatando as avaliaçóes de seis fornecedores da empresa.

Para os seis fornecedores escolhidos, foram obtidos escores médios para os quatro construtos examinados: impacto do fornecedor nos resultados da cadeia; complexidade na gestão do fornecedor; dependências entre fornecedor e empresa; e saúde financeira do fornecedor. Com os escores médios, foram construídas três matrizes: impacto x complexidade; impacto $\mathrm{x}$ dependência; e impacto $\mathrm{x}$ saúde financeira. Conforme o quadrante das matrizes em que o fornecedor se localizou, açôes de correção e prevenção dos riscos encontrados foram sugeridas para a empresa. Dos seis fornecedores quatro foram diagnosticados como em situação de risco. Pelo sis- tema anterior de avaliação, que considerava apenas a relaçáo entre impacto nos resultados e risco de desabastecimento, a situação de risco destes fornecedores não teria sido percebida. Açôes de correção foram tomadas e novas avaliaçóes foram feitas. Nem todos os fornecedores apresentaram evoluçáo positiva: alguns apenas trocaram de posição, porém sem vantagem para a SCM. No entanto, devido às trocas de posição observadas, é necessário trocar também a abordagem de gestão destes fornecedores. Um dos casos estudados desinteressou-se em continuar na cadeia, devido às exigências de gestão que foram impostas pelo sistema.

Como continuidade de pesquisa, sugere-se relatar o caso dos seis fornecedores longitudinalmente, ou seja ao longo do tempo. Já há avaliaçôes suficientes ao longo de quatro anos para formar casos em profundidade contando a história dos fornecedores e o resultado das açôes de correçáo que o sistema de classificação permitiu formular. Também sugere-se estender o sistema atual para fornecedores de serviços, pois atualmente é concebido e formatado exclusivamente para fornecedores de matéria-prima. Por fim, sugere-se flexibilizar o pressuposto de que todos os construtos e todos os indicadores tenham a mesma importância. Neste caso, sugere-se a adoção de um método multicriterial de apoio à decisão para a distribuição de importância relativa entre indicadores e construtos.

\section{REFERÊNCIAS}

Alves Filho, A.; Cerra, A.; Maia, J.; Sacomano Neto, M.; Bonadio, P. (2004) Pressupostos do Gerenciamento da Cadeia de Suprimentos: evidências de estudos sobre a indústria automobilística. Gestão \& Produção, v.11, n.3, p.275-288.

Beamon, B. (1998) Supply Chain Design and Analysis: Models and Methods. International Journal of Production Economics, v.55, n.3, p.281-294.

Beck, F.; Silva, D.; Corcini Neto, S.; Sellitto, M.; Pereira, G. (2009) Classificação estratégica de fornecimentos de uma operaçáo de manufatura segundo critérios de volume e variabilidade. Anais do XXIX ENEGEP. Salvador: ABEPRO.

Brown, R. (1967) Decision rules for inventory management. EUA: Arthur D. Little.

Cheung, Y.; Rowlinson, S. (2011) Supply chain sustainability: a relationship management approach. International Journal of Managing \& Projects in Business, v.4, n.3, p.480-497. 
Chopra, S.; Meindl, P. (2003) Supply chain management: strategy, planning and operations. New York: Prentice Hall.

Chow, W.; Madu, C.; Kuei, C.; Lu, M.; Lin, C.; Tseng, H. (2008) Supply chain management in the US and Taiwan: An empirical study. Omega, v.36, n.5, p.665-679.

Dornier, P.; Ernst, R.; Fender, M.; Kouvelis, P. (2000) Logística e operaçóes globais: texto e casos. S. Paulo: Atlas.

Ellram, L.; Carr, A. (1994) Strategic purchasing: a history and review of literature. International Journal of Purchasing and Materials Management, v.30, n.2, p.10-18.

Fu, Y.; Piplani, R. (2004) Supply-side collaboration and its value in supply chains. European Journal of Operational Research, v.152, n.1, p.281-288,

Giannakis, M.; Louis, M. (2011) A multi-agent based framework for supply chain risk management. Journal of Purchasing and Supply Management, v.17, n.1, p.23-31.

Gonçalves, P. (2007) Administração de materiais. R. Janeiro: Campus.

Green, K.; Morton, B.; New, S. (1996) Purchasing and environmental management: interactions, policies and opportunities. Business Strategy and the Environment, v.5, n.3, p.188-197.

Hahn, G.; Kuhn, H. (2012) Value-based performance and risk management in supply chains: A robust optimization approach. International Journal of Production Economics, v.139, n.1, p.135-144.

Handfield, R.; Krause, D.; Scanell, T.; Monzka, R. (2000) Avoid the Pitfalls in Supplier Development. Sloan Management Review, v.41, n.2, p.37-49.

Humphreys, P.; Shiu, W.; Chan, F. (2001) Collaborative Buyer-Supplier Relationships in Hong Kong Manufacturing Firms. Supply Chain Management: An International Journal, v.6, n.4, p.152-162.

Klippel, M.; Antunes Jr., J.; Vaccaro, G. (2007) Matriz de posicionamento estratégico de materiais: conceito, método e estudo de caso. Gestão \& Produção, v.14, n.1, p.181-192.

Lambert, D. (2008) Supply Chain Management: Processes, Partnerships, Performance. Sarasota: Supply Chain Management Institute.

Lambert, D., Cooper, M. (2000) Issues in Supply Chain Management. Industrial Marketing Management, v.29, n.1, p.65-83.
Lee, H.; Billington, C. (1995) The evolution of supply chain management models and practice at Hewlett-Packard. Interfaces, v.23, n.5, p. 42-63.

Lummus, R.; Vokurka, R.; Alber, K. (1998) Strategic Supply Chain Planning. Production and Inventory Management Journal, v.39, p.49-58.

Möller, K.; Törrönen, P. (2003) Business suppliers' value creation potential: a capability-based analysis. Industrial Marketing Management, v.32, n.2, p.109-118.

Moon, J.; Tikoo, S. (2002) Buying decision approaches of organizational buyers and users. Journal of Business Research, v.55, n.4, p.293-299.

Pedroso, M. (2002) Um estudo sobre o desenvolvimento de competências em Gestão de Cadeia de Suprimentos. Tese (Doutorado em Engenharia de Produção) - Escola Politécnica, Universidade de São Paulo. São Paulo.

Pires, S. (1998) Managerial implications of the modular consortium in a Brazilian automotive plant. International Journal of Operations \& Production Management, v.18, n.3, p.221-232.

Pires, S. (2004) Gestão da cadeia de suprimentos (supply-chain management): conceitos, estratégias, práticas e casos. São Paulo: Atlas.

Porter, M. (1998) Estratégia competitiva: técnicas para análise de indústrias e da concorrência. R. Janeiro: Campus.

Roesch, S. (1999) Projetos de estágio e de pesquisa em administração: guia para estágios, trabalhos de conclusão, dissertaçôes e estudos de caso. S. Paulo: Atlas.

Rosa, E.; Sellitto, M.; Mendes, L. (2006) Avaliação multicriterial de desempenho e separação em aglomerados de fornecedores críticos de uma manufatura OKP. Produção, v.16, n.3, p.413-428.

Scavarda, L.; Hamacher, S. (2001) Evolução da cadeia de suprimentos da indústria automobilística no Brasil. Revista de Administração Contemporânea, v.5, n.2, p.201-219.

Sellitto, M.; Borchardt, M.; Pereira, G.; Pacheco, D. Gestão de cadeias de suprimentos verdes: quadro de trabalho e direção para futura pesquisa. Produção Online (aguarda publicação).

Sellitto, M.; Borchardt, M.; Pereira, G. (2011) Systemic performance assessment of a kind of complex adaptive system: supply-chains. Proceedings of the 2th IMCIC 2011, International Multi-Conference on Complexity, Informatics and Cybernetics. Orlando: International Institute of Informatics and Systemics. 
Sellitto, M. (2005) Medição e controle de desempenho estratégico em sistemas de manufatura. Tese (Doutorado em Engenharia de Produção). Escola de Engenharia, UFRGS, Porto Alegre.

Slack, N. (2002) Vantagem competitiva em manufatura. S. Paulo: Atlas.

Sodhi. M.; Son, B.; Tang, C. (2012) Researchers' Perspectives on Supply Chain Risk Management. Production and Operations Management, v. 21, n.1, p.1-13

Souza, D.; Kliemann Neto, F.; Anzanello, M. (2012) Avaliaçáo de desempenho da cadeia de suprimentos balizada por critérios de competitividade empresarial. Produção Online, v.12, n.3, p.756-778.

Stevens, G. (1989) Integrating the Supply Chains," International Journal of Physical Distribution and Material Management, v.8, n.8, p.3-8.

Swaminathan, J.; Smith, S.; Sadeh, N. (1996) A Multi Agent Framework for Modeling Supply Chain Dynamics. Working Paper, The Robotics Institute, Carnegie Mellon University.
Tan, K.; Kannan, V.; Handfeld, R. (1998) Supply Chain Management: Supplier Performance and Firm Performance. International Journal of Purchasing and Materials Management, v.34, n.3, p.2-9.

Tang, O.; Musa, S. (2011) Identifying risk issues and research advancements in supply chain risk management. International Journal of Production Economics, v.133, n.1, p.25-34.

Vilko, J.; Hallikas, J. (2012) Risk assessment in multimodal supply chains. International Journal of Production Economics, v.140, n.2, p.586-595.

Yin, R. (2001) Estudo de caso: planejamento e método. P. Alegre: Bookman.

Zsidisin, G.; Ellram, L.; Carter, J.; Cavinato, J. (2004) An analysis of supply risk assessment techniques. International Journal of Physical Distribution \& Logistics Management, v.34, n.5, p. 397-413. 